5. Luna Rodríguez C, Menárguez Puche J, Alcántara Muñoz P, Aroca García MD, Aguilar Mrtínez J. Infraestructura existente en atención primaria de Murcia para la práctica de cirugía menor. Granada: Congreso Internacional de Medicina Familiar y Comunitaria, 13-16 de noviembre, 1996.

6. Arribas Blanco JM, Gil Sanz ME, Sanz Rodrigo C, Morón Merchante I, Muñoz-Quirós Aliaga S, López Romero A, et al. Efectividad de la cirugía menor dermatológica en la consulta del médico de familia y satisfacción del paciente en relación con la cirugía ambulatoria. Med Clin (Barc) 1996; 107: 772-5.

7. López Santiago A, Lara Peñaranda R, De Miguel Gómez A, Pérez López P, Ribes Martínez E. Cirugía menor en atención primaria: la satisfacción de los usuarios. Aten Primaria 2000; 26: 91-5.

\section{Neumomediastino espontáneo idiopático: a propósito de un caso}

\section{Sr. Director:}

La presencia de aire extraluminal en el espacio mediastínico sin que se demuestre trau- matismo previo ni enfermedad pulmonar subyacente se conoce como neumomediastino espontáneo, entidad ya descrita por Macklin en $1939^{1,2}$.

Presentamos el caso de un varón de 21 años que, desde hace tres días, presenta dolor torácico retroesternal, de intensidad progresiva, que aumenta con la inspiración profunda, acompañado de dificultad para tragar y cambios en la tonalidad de la voz. En la exploración se encontró crepitación a la palpación cervical y supraclavicular bilateral con disminución global del murmullo vesicular. En la anamnesis se comprobó la presencia de vómitos de repetición en días previos.

El neumomediastino se puede producir de forma espontánea $(30 \%)$ o como resultado de traumatismos u otros procesos patológicos (Tabla I).

El diagnóstico se basa en la sospecha clínica, la exploración física y las pruebas complementarias de analítica e imagen ${ }^{2}$.

El $85 \%$ de los casos aparece en varones de entre 15 y 40 años y se manifiesta como dolor torácico retroesternal, opresivo, de inicio brusco, irradiado a miem- bro superior izquierdo, hombro, cuello y espalda, de duración variable (desde minutos hasta horas), que aumenta con la inspiración profunda, la tos y los movimientos.

Otros signos y síntomas son: disnea $(80 \%)$, disconfort cervical $(20 \%)$ con dolor de garganta, dolor o hinchazón del cuello, cambios en el tono de la voz o dificultad para tragar, enfisema subcutáneo $(90 \%)$ y/o el signo de Hamman (crepitación a la auscultación retroesternal sincrónica con el latido y que se modifica con la inspiración y la posición) $)^{3-6}$.

Las pruebas analíticas de urgencia (hemograma, bioquímica elemental y gasometría arterial basal) y el electrocardiograma suelen ser normales. En la radiografía simple de tórax, posteroanterior y lateral, se manifiesta como aparición de burbujas de gas rodeando las estructuras mediastínicas. Los signos radiológicos clásicos (Figs. 1 y 2) son el signo del diafragma continuo (presencia de aire entre pericardio y diafragma), el signo de la $\mathrm{V}$ de Naclerio (presencia de aire entre aorta descendente y hemidiafragma izquierdo) y, en niños, el

\title{
Tabla I
}

CAUSAS DE NEUMOMEDIASTINO

\begin{tabular}{|c|c|c|}
\hline Patogenia & Condición subyacente & Causa \\
\hline \multirow[t]{7}{*}{$\begin{array}{l}\text { Rotura alveolar asociada a } \\
\text { presión alveolar alta }\end{array}$} & Obstrucción de la vía aérea & $\begin{array}{l}\text { Asma, cuerpos extraños, } \\
\text { laringitis aguda obstructiva, } \\
\text { estenosis congénita }\end{array}$ \\
\hline & Ventilación mecánica & $\begin{array}{l}\text { Anestesia general, } \\
\text { presión positiva al final de la espiración }\end{array}$ \\
\hline & Maniobras respiratorias bruscas & $\begin{array}{l}\text { Actividad estenuante, acidosis, } \\
\text { maniobras de capacidad vital }\end{array}$ \\
\hline & Traumatismos torácicos & Lesiones penetrantes \\
\hline & Maniobras de Valsalva & $\begin{array}{l}\text { Coger pesos, defecación, maniobra de } \\
\text { Heimlich, parto, inhalación de } \\
\text { cocaína y marihuana }\end{array}$ \\
\hline & Vómitos & Cetoacidosis diabética, anorexia nerviosa \\
\hline & Cambios de presión atmosférica & $\begin{array}{l}\text { Cambios rápidos de altitud, } \\
\text { Enfermedad de Caisson }\end{array}$ \\
\hline
\end{tabular}


Tabla I

\section{CAUSAS DE NEUMOMEDIASTINO (continuación)}

\begin{tabular}{|c|c|c|}
\hline Patogenia & Condición subyacente & Causa \\
\hline $\begin{array}{l}\text { Rotura alveolar asociada a } \\
\text { enfermedad alveolar }\end{array}$ & $\begin{array}{l}\text { Infecciones } \\
\text { Aspiración } \\
\text { Distrés respiratorio del adulto } \\
\text { Enfisema } \\
\text { Enfermedades intersticiales } \\
\text { pulmonares }\end{array}$ & $\begin{array}{l}\text { Bacterias, virus, mycobacterias, } \\
\text { abscesos pulmonares } \\
\text { Sarcoidosis, silicosis }\end{array}$ \\
\hline Alteraciones traqueobronquiales & $\begin{array}{l}\text { Traumatismos } \\
\text { Instrumentación } \\
\text { Neoplasias }\end{array}$ & Biopsia broncoscópica \\
\hline Perforación esofágica & $\begin{array}{l}\text { Síndrome de Boerhaave } \\
\text { Yatrogenia } \\
\text { Traumatismos penetrantes } \\
\text { Neoplasias }\end{array}$ & \\
\hline $\begin{array}{l}\text { Traumatismos y cirugía de } \\
\text { cabeza y cuello }\end{array}$ & $\begin{array}{l}\text { Perforación nasofaríngea } \\
\text { Fracturas del macizo facial } \\
\text { Procedimientos dentales } \\
\text { Cirugía }\end{array}$ & $\begin{array}{l}\text { Intubación traumática } \\
\text { Intervención de lengua y tiroides } \\
\text { Traqueostomía }\end{array}$ \\
\hline $\begin{array}{l}\text { Traumatismos y cirugía } \\
\text { abdominal y retroperitoneal }\end{array}$ & $\begin{array}{l}\text { Perforación intestinal } \\
\text { Diverticulitis } \\
\text { Hernias } \\
\text { Cirugía de recto-sigma } \\
\text { Traumatismos abdominales }\end{array}$ & \\
\hline
\end{tabular}

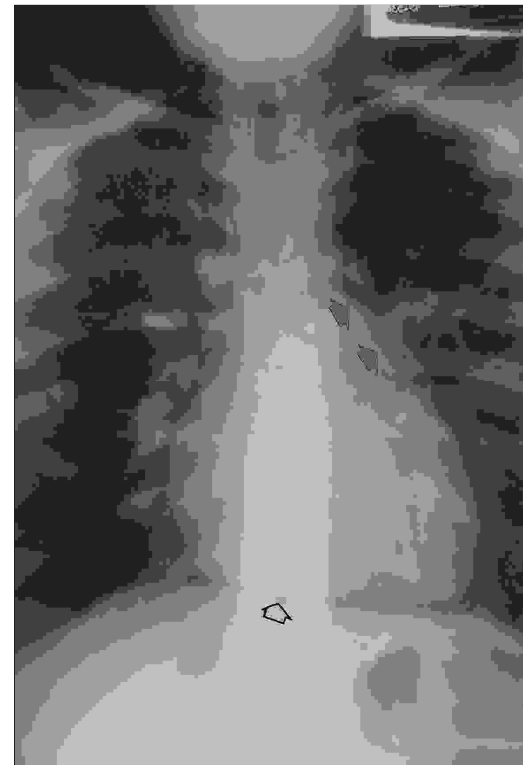

Figura 1

En la proyección posteroanterior de tórax se observa aire rodeando el arco aórtico y la arteria pulmonar; también se observa aire entre el corazón y el diafragma (signo del diafragma continuo).

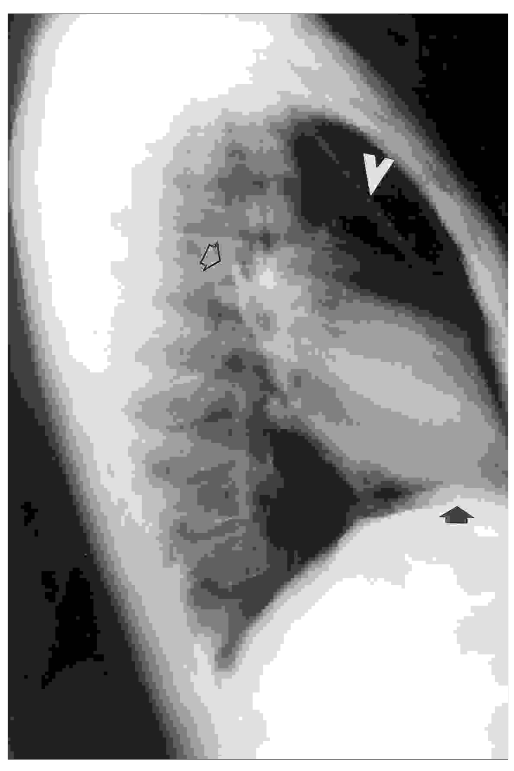

Figura 2

En la proyección lateral de tórax se observa aire rodeando arteria pulmonar, aorta descendente, tráquea y remanente tímico (signo de la vela); también se observa aire en la cara superior del hemidiafragma izquierdo (signo del diafragma continuo). 


\begin{tabular}{|l|l|}
\hline \multicolumn{1}{|c|}{ DIAGNÓSTICO DIFERENCIAL DEL DOLOR TORÁCICO } \\
\hline Cardiacas & $\begin{array}{l}\text { Coronariopatías } \\
\text { Estenosis aórtica } \\
\text { Miocardiopatía hipertrófica } \\
\text { Pericarditis }\end{array}$ \\
\hline Vasculares & $\begin{array}{l}\text { Disección aórtica } \\
\text { Embolia pulmonar } \\
\text { Hipertensión pulmonar severa } \\
\text { Sobrecarga ventricular derecha }\end{array}$ \\
\hline Pleuropulmonares & $\begin{array}{l}\text { Pleuritis o neumonía } \\
\text { Traqueobronquitis } \\
\text { Neumotórax } \\
\text { Neumomediastino } \\
\text { Mediastinitis }\end{array}$ \\
\hline Gastrointestinales & $\begin{array}{l}\text { Reflujo gastroesofágico } \\
\text { Espasmo esofágico } \\
\text { Síndrome de Mallory-Weiss } \\
\text { Enfermedad ulcerosa péptica } \\
\text { Afección de vesícula y vías biliares } \\
\text { Pancreatitis }\end{array}$ \\
\hline Otras & $\begin{array}{l}\text { Hernia de disco vertebral } \\
\text { Artritis de hombro o columna } \\
\text { Osteocondritis esterno-costal y síndrome de Tietze } \\
\text { Síndromes interescalénicos o de hiperabducción } \\
\text { Bursitis subacromial }\end{array}$ \\
\hline & $\begin{array}{l}\text { Trastornos de la mama } \\
\text { Ansiedad-depresión }\end{array}$ \\
\hline &
\end{tabular}

signo de la vela (aire delimitando el timo $)^{7}$. La TAC torácica se ha demostrado superior a la radiografía simple, tanto en el diagnóstico, localización y extensión del neumomediastino como en el diagnóstico diferencial, sobre todo en pacientes graves ${ }^{8}$. El diagnóstico diferencial debe realizar- so relativo durante ocho o diez días, no siendo necesario el ingreso hospitalario.

\section{Castaño Yubero, L. Gómez \\ de Montes, T. Guerra Garijo*, D. Oquillas Izquierdo*}

Servicios de Urgencias y de *Radiodiagnóstico. Hospital General de Segovia

\section{BIBLIOGRAFÍA}

1. Macklin CC. Transport of air along sheats of pulmonic blood vessels from alveoli to mediastinum. Arch Intern Med 1939; 64: 913-91.

2. Maunder RJ, Pierson DJ, Hudson LD. Subcutaneous and mediastinal emphysema. Pathophisiolgy, diagnosis and management. Arch Intern Med 1984; 144: 1447-53.

3. Hernandez JA, Sanz F, Mateos A, Ruiz R, Querol R, De Portugal J. Neumomediastino espontáneo. Rev Clin Esp 1985; 176(1): 51-2.

4. Blanquer J, Chilner E, Núñez C, Blanquer R, Muñoz J. Neumomediastino espontáneo del adulto. Rev Clin Esp 1990; 187(1): 22-4.

5. Bratton SL, O’Rourke PP. Spontaneous pneumomediastinum. J Emerg Med 1993; 11(5): 525-9.

6. Panacek EA, Singer AJ, Sherman BW, Prescott A, Rutherford W. Spontaneous. Pneumomediastinum: clinical and natural history. Ann Emerg Med 1992; 21(10): 1222-7.

7. Bejvan SM, Goswin JD. Pneumomediastinum: old and new signs. AJR 1996; 166: 1041-8.

8. Martin MF, Hlaawatsch A, Heussel CP, Schwaden F, Kauczor HU. The radiologic findings in pneumomediastinum. Value of conventional radiography and comparison with computerized tomography. Radiologia 1997; 39(10): 709-14. 